\title{
La práctica artística como lugar de visibilización de las mujeres transgénero de Pereira (Colombia)
}

\author{
Sandra Johana Silva-Cañaveral' ${ }^{\text {(iD }}$ 0000-0002-5805-359X \\ 'Universidad del Valle, Departamento de Artes Visuales y Estética, Cali, Valle del \\ Cauca, Colombia. 25360 -sandra.silva@correounivalle.edu.co
}

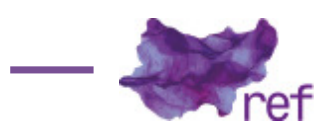
Resumen: La práctica artística ha privilegiado la experiencia de lo 'vivido' por las mujeres y por otros
sujetos, porque ella en sí misma es un saber de la experiencia humana. Esta abertura sensible a lo
'vivido' permite abarcar en el ejercicio de la creación a todos los seres humanos, así como a todas las
esferas en las que experimentan su subjetividad. El propósito de este artículo consiste en mostrar los
resultados de la investigación-creación llevada a cabo con cinco mujeres transgénero y una comunidad
de creadores y creadoras en la ciudad de Pereira, Colombia, cuyos registros estéticos y artísticos
produjeron nuevas operaciones simbólicas y cognitivas al convertir la experiencia de lo 'vivido' en una
urdimbre de visibilización, interlocución y reivindicación de las subjetividades y de sus identificaciones
cognitivas, sociales, políticas, sexuales y de género.

Palabras clave: mujeres transgénero; Vestidos Orales; género y sexualidad; investigación-creación; investigación artística.

Artistic Practice as a Place of Visibility of Transgender Woman from Pereira (Colombia) Abstract: The artistic practice has privileged the experience of the "lived" by women and other subjects because such practice is in itself a knowledge of human experience. This sensitive opening to the "lived" allows to embrace, in the creative exercise, all human beings, as well as all the spheres in which they experience their subjectivity. The purpose of this article is to show the results of the research-creation carried out with five transgender women and a community of men and women creators in the city of Pereira, Colombia, whose aesthetic and artistic records produced new symbolic and cognitive operations when converting the experience of the "lived" into a weave of visibility, interlocution and vindication of the subjectivities and their cognitive, social, political, sexual and gender identifications.

Keywords: Transgender women; Gender and sexuality; Vestidos Orales; Research-creation; Artistic research.

Prática artística como local de visibilização das mulheres transgênero de Pereira (Colômbia)

Resumo: A prática artística tem beneficiado a experiência do 'vivido' pelas mulheres e por outros indivíduos, devido a que ela, em si mesma, é um conhecimento sobre a experiência humana. Essa abertura sensível do 'vivido' permite incluir todos os seres humanos no exercício da criação, igualmente todas as esferas nas quais eles vivenciam a sua subjetividade. O objetivo deste artigo é divulgar os resultados de uma pesquisa-criação realizada com cinco mulheres transgênero e uma comunidade de criadores e criadoras na cidade de Pereira, Colômbia, cujos registros estéticos e artísticos obtidos resultaram em novas operações simbólicas e cognitivas, transformando a experiência do 'vivido' em um tecido de visibilização, interlocução e reivindicação das subjetividades e das suas identificações cognitivas, sociais, políticas, sexuais e de gênero.

Palavras-chave: mulheres transgênero; Vestidos Orales; gênero e sexualidade; pesquisa-criação; pesquisa artística. 


\section{Introducción}

A la mujer, al igual que a las identidades queer, les ha tomado muchas décadas insertarse en el escenario académico tanto como en el escenario profesional. Mostrar que el conocimiento y lo femenino son asuntos convergentes no ha sido el único desafío para las mujeres. Para Diana Maffía (2007), la posición hegemónica de los hombres en el discurso de la ciencia y el arte, los embates culturales y biológicos entre sexo y género y la atribución de condiciones emocionales que restan valor epistémico a sus contribuciones han retrasado la llegada de las mujeres a la vida profesional tanto como a las comunidades académicas.

Siguiendo a Maffía, cuatro posiciones conceptuales han instado a la marginalidad de las mujeres en el campo del conocimiento: la primera tiene que ver con la falta de reconocimiento a sus aportes científicos; la segunda, con el limitado acceso a los recursos científicos y a una posición profesional equitativa; la tercera, se refiere a la cristalización de verdades que ciencias como la medicina y la biología han formulado sobre la naturaleza física, emocional y psicológica de las mujeres, con las cuales liquidan su valía como sujetos pensantes; y la cuarta, a la discriminación basada en el género, pues la ciencia ha sido inminentemente masculina.

En Ciencia y feminismo, Sandra Harding (1996) hace manifiesto el sentido androcéntrico de la ciencia, así como la influencia del género en la división del trabajo, la construcción de las identidades individuales y la producción del conocimiento. Según la autora, esta postura se encuentra enraizada en las modernas culturas occidentales que han valorado lo masculino como una característica natural y positiva, inherente al carácter progresista de la racionalidad científica. Por ello, sus búsquedas se han enfocado en la elaboración de nuevos significados y prácticas emancipadoras que promuevan, en un discurso renovado de la ciencia, los valores de las mujeres como elemento fundamental de la experiencia humana. Entre otras cosas, porque traería consigo reivindicaciones más solidarias e incluyentes con todas las identidades que fueron marginadas y fragmentadas en el proyecto de la modernidad.

Los movimientos feministas contraculturales de los años sesenta y setenta, sumados a los discursos gestados en el interior de los movimientos feministas actuales, han dado cuenta de la diferencia de género como el principal obstáculo en las concepciones científicas y artísticas.

En La tecnología del género, Teresa De Lauretis (1989) advierte sobre el peso cultural y político de la noción de género en relación con la diferencia sexual dentro del campo cognitivo de las ciencias naturales, sociales y humanas. Al mismo tiempo señala la aparición de prácticas, espacios y discursos que reflexionan acerca de esa diferencia sexual y de su limitación dentro del mismo pensamiento feminista.

La diferencia sexual definida por De Lauretis (1989) como "una diferencia de las mujeres respecto de los varones, de lo femenino respecto de lo masculino" (DE LAURETIS, 1989, p. 7) localiza sus limitaciones. Primero, en la difícil tarea de identificar y reconocer las diferencias dentro de las mujeres. Judith Butler (2007) arguye que la categoría mujer no es un significante estable. Por el contrario, es motivo de angustia en tanto no alcanza a invocar la diversidad de lo que implica ser y representarse como mujer. Ahora bien, aceptar una representación más extensa de ese sujeto del feminismo implica entender que "la distinción sexo/género muestra una discontinuidad radical entre cuerpos sexuados y géneros culturalmente construidos" (BUTLER, 2007, p. 54). Esto quiere decir que una mujer transgénero es también un sujeto del feminismo, a pesar de que haya nacido de sexo masculino.

Una mujer de Occidente es muy diferente de una mujer de Oriente. La experiencia contextual e histórica reafirma en cada una su diversidad cultural, social, política y cognitiva. Su diferencia. Si no se consolidan estas diferencias como un terreno de interés para el pensamiento feminista, en opinión de De Lauretis, "todas las mujeres no serían sino copias de diferentes personificaciones de algunas arquetípicas esencias de mujer" (DE LAURETIS, 1989, p. 2).

Y segundo, la autora apunta otra limitación en el reconocimiento multidimensional de la subjetividad y de su proceso cognitivo. Un sujeto de conocimiento instala su potencial cognitivo en el campo de lo epistémico, desde su condición sexual y de género, pero también desde su pertenencia a una comunidad; de su raza, posición ideológica y religiosa: "un sujeto, en consecuencia, no unificado sino múltiple" (DE LAURETIS, 1989, p. 2).

De ahí que Butler insista en afirmar que el género no es el único eje de relación que conforma y entrecruza a las identidades, pero tampoco es un asunto desconectado del resto de las dimensiones humanas y mucho menos de las "intersecciones políticas y culturales en la que constantemente se produce y se mantiene" (BUTLER, 2007, p. 49).

Lo que sugiere De Lauretis frente a esta disyuntiva entre género y sexo, es una noción de género más amplia y desligada de esa contención con la diferencia sexual.

En tal sentido, la tarea que se propone este artículo va en dos direcciones: primero, la búsqueda y reconocimiento de las posiciones (discursivas, estéticas y artísticas) de las mujeres transgénero que han encontrado en el campo de la creación artística un lugar de visibilización. Y 
segundo, una reflexión sobre la práctica artística como la dimensión para pensar en las mujeres transgénero como sujetos de conocimiento a través de la experiencia derivada de la obra Vestidos Orales. Dos posiciones desde las cuales se pretende argumentar que el arte es un campo de visibilización y experimentación de los saberes y conocimientos de los sujetos marginados de la construcción de sentido.

\title{
2 Proceso metodológico
}

La investigación-creación, o investigación artística, o investigación guiada por la práctica, o práctica como investigación, nombres con los cuales se le conoce en otros contextos mundiales, fue el método empleado para llevar a cabo esta propuesta de naturaleza creativa e investigativa (Henk BORGDORFF, 2006; Graeme SULLIVAN, 2005; Fernando HERNÁNDEZ, 2008; Ligia ASPRILLA, 2013; Darren NEWBURY, 2012; Robin NELSON, 2013).

En Colombia, la investigación-creación se ha configurado como el camino para validar el conocimiento sensible dentro del contexto universitario. Esta definición que valora la creación como un camino garante en la producción de conocimiento en el ámbito de las disciplinas creativas (artes, diseño, arquitectura, cine y nuevos medios), es también un concepto entretejido a la idea de un "modelo de relación entre los seres humanos y sus contornos de saber, que forma y deforma el conocimiento sensible desde lo individual, lo grupal y lo social" (Sandra SILVA, 2016, p. 54).

Con el fin de ofrecer una exposición precisa del término investigación-creación se incluye la definición consignada en la política nacional de ciencia, tecnología e innovación de Colombia:

\begin{abstract}
Es la indagación que busca responder a una pregunta o problema de investigación a través de una experiencia creativa que da lugar a obras, objetos o productos con valor estético y cuya naturaleza temporal puede ser efímera, procesual o permanente. En otras acepciones se considera que la investigación-creación - también llamada investigación artística, o investigación basada en la práctica - es aquella indagación que toma como objeto a la experiencia estética del propio investigador-creador, por lo cual siempre tiene un componente autorreflexivo (Borgdorff 2006; Asprilla 2013; Hernández Salgar 2014). Este énfasis en la experiencia, así como el carácter dinámico y relacional de la obra, hacen que la investigación-creación presente diferencias a nivel epistemológico, metodológico y ontológico con la investigación científica (Hannula et al. 2005; Borgdorff 2006). La investigación-creación conduce, por lo general a dos tipos de productos, la obra, objeto o producto de creación propiamente dicha y un texto en el cual se consigna la reflexión sobre la experiencia creativa y su relación con la pregunta o problema de investigación (Archer 1995; López-Cano 2013). (COLCIENCIAS, 2015, p. 126)
\end{abstract}

Dado que en la investigación-creación los sistemas, artefactos y estrategias de recolección sensible están por inventar, es decir, cada creador o creadora debe ocuparse de diseñar sus propios instrumentos de recolección sensible de acuerdo con los intereses y requerimientos de sus indagaciones y la naturaleza de los productos que derivan de sus disciplinas, su valor cognitivo se cristaliza en la producción de ese cuerpo metodológico y de esos ejercicios-objetosacontecimientos estéticos-artísticos que emergen del proceso. Henk Borgdorff (2006) se refiere a la creación de estas herramientas artísticas de investigación como una "cuestión metodológica" conexa al hecho epistemológico y ontológico, mediante el cual la investigación artística configura objetos, procesos y contextos inconmensurables desde la perspectiva de otros campos de conocimiento, pero no por ello, ilegítimos como investigación.

La práctica artística puede ser calificada como investigación si su propósito es aumentar nuestro conocimiento y comprensión, llevando a cabo una investigación original en y a través de objetos artísticos y procesos creativos. La investigación de arte comienza haciendo preguntas que son pertinentes en el contexto investigador y en el mundo del arte. Los investigadores emplean métodos experimentales y hermenéuticos que muestran y articulan el conocimiento tácito que está ubicado y encarnado en trabajos artísticos y procesos artísticos específicos. Los procesos y resultados de la investigación están documentados y difundidos de manera apropiada dentro de la comunidad investigadora y entre un público más amplio. (BORGDORFF, 2006, p. 27)

De otro lado, Darren Newbury (2012) se conecta a la discusión empleando los términos 'ideas' y 'evidencias' para referirse a los componentes que integran no solo la investigación artística, sino, por supuesto, su cuerpo metodológico. De acuerdo con el autor, esas 'ideas' y 'evidencias' - cuya característica principal estriba en que son elaboradas a partir de las materialidades propias de las artes o el diseño - deben estar articuladas dentro de una relación dialógica de sentido.

Por tal razón, la investigación-creación no solo fue el camino idóneo para darle soporte epistemológico a esta propuesta, sino que, además, fue la estrategia metodológica para producir sinergias intelectuales con otros campos disciplinares y, en consecuencia, con otros investigadorescreadores. 
El sistema metodológico que dio soporte a esta propuesta académica, que además se dividió en componente investigativo y componente creativo, incorporó la creación como elemento fundante y vertebral a toda la experiencia. Eso significa que tanto el componente investigativo como el creativo dieron origen a artefactos de naturaleza artística.

Desde la perspectiva del componente investigativo se elaboraron dos estrategias artísticas de participación ciudadana: una cartografía simbólica del miedo y un fobófono.

La cartografía simbólica del miedo consistió en un mapa de la ciudad de Pereira, conformado por los barrios formales e informales, y completado con unas convenciones o símbolos relacionados con los comportamientos sociales asociados a los espacios 'miedosos' o 'peligrosos'. Este recurso metodológico arrojó como resultado que el parque La Libertad era el territorio más miedoso de la ciudad. Mientras que, con el fobófono, un dispositivo de audio utilizado para capturar las percepciones orales acerca de lo que produce miedo en el parque La Libertad e inventado durante el proceso artístico a partir de la unión entre la palabra griega Fobos, que traduce miedo, y la palabra Fono, que significa secuencia sonora, se supo que las mujeres transgénero (o travestis, como les dicen coloquialmente) eran los agentes productores de miedo en ese territorio. Fue así como se encontró a Leidy (de 51 años de edad, proveniente de la ciudad de Aguadas- Caldas, antes conocida como José Uriel Lodoño), Gia (de 30 años de edad, proveniente de la ciudad de Pereira-Risaralda, antes conocida como Alexander Gil), Valeria (de 39 años de edad, proveniente de Chinchiná-Caldas, antes conocida como Yesid Salazar), Yuri (de 34 años de edad, proveniente de Pereira-Risaralda, antes conocida como Darwin Muñoz) y Diana (de 56 años de edad, proveniente de Montenegro-Quindío, antes conocida como Julio César Morales), las cinco mujeres transgénero provenientes del parque La Libertad con quienes se edificó la experiencia estéticoartística. En esta investigación-creación, el concepto de 'territorio del miedo' fue la categoría de entrada a una indagación sobre mujeres transgénero y arte contemporáneo. Esto quiere decir que las mujeres transgénero no fueron elegidas de manera arbitraria o predeterminada, sino más bien llegaron a la investigación, y posteriormente a la creación, mediante estas dos estrategias artísticas de participación ciudadana que las develó como agentes productores de miedo en un territorio.

En lo que respecta al componente creativo, se formularon tres productos artísticos: la obra de arte Vestidos Orales, sobre la cual se centra la reflexión en este artículo, un video documental con el registro de todo el proceso de investigación-creación que lleva el nombre de Vestidos Orales y una crónica audiovisual enfocada en la vida de Leidy Londoño, lideresa de las mujeres transgénero del parque La Libertad, titulada Días de Afrodita.

Cabe anotar que este proceso de investigación-creación fue llevado a cabo desde 2012 hasta 2016 , con estudiantes, profesores y profesoras adscritos a los semilleros de investigación de la Facultad de Diseño, Comunicación y Bellas Artes de la Fundación Universitaria del Área Andina, seccional Pereira.

\section{Mujeres transgénero que viven y laboran en el parque La Libertad de la cludad de Pereira, Colombia}

Cada ciudad posee una manera particular de configurar sus tejidos afectivos y sus contenidos simbólicos sobre las identidades. Cuando el revestir de sentido a esas identidades se deja en manos de los ciudadanos y las ciudadanas, emergen una serie de representaciones que dotan a los sujetos de unas cualidades estéticas, sociales y culturales divergentes.

La ciudad de Pereira, lugar en el que emerge esta investigación-creación y que da cuerpo al acontecimiento artístico, es la capital del Departamento de Risaralda. Se encuentra ubicada en el interior de Colombia, en la región montañosa formada por la cordillera de los Andes. Comparte junto a dos ciudades capitales, Manizales (Caldas) y Armenia (Quindío), el privilegio de integrar el Eje Cafetero, denominación recibida por ser la principal región productora de café en Colombia. También se caracteriza por haber vivido, en los últimos veinte años, un proceso de rediseño estratégico de su infraestructura urbana y de movilidad bajo los presupuestos de la renovación urbana; fenómeno a través del cual justificó la reacomodación de espacios urbanos humanos y sostenibles como la plaza de mercado aledaña al parque La Libertad, lugar que alojaba a grupos humanos desfavorecidos y desatendidos por el Estado, entre ellos las mujeres cisgénero y transgénero en ejercicio laboral sexual. Estas reacomodaciones espaciales generaron aislamiento, desplazamiento y migración de los individuos dentro de la misma ciudad, pero también, la autogestión de territorios hostiles y degradados que surgieron como respuesta a la inequidad y la exclusión (Luis Adolfo MARTíNEZ, 2012).

Interesados en conocer esas representaciones (perceptuales, narrativas y estéticas) que los habitantes de Pereira tienen sobre las mujeres transgénero que viven y laboran en el parque La Libertad, territorio rehabilitado por la renovación urbana, y luego de haber llevado a cabo dos estrategias artísticas de participación ciudadana (cartografía simbólica del miedo y fobófono), los creadores y creadoras encontraron que muchas de esas representaciones se forman por imaginario, por pedagogía y por conocimiento científico. 
Una mujer transgénero en ejercicio laboral sexual dentro de un territorio del miedo está sujeta a una triple discriminación: por su identidad de género (ser transgénero significa negar la designación cultural del género, así como de las conductas heterosexuales, sociales, morales y jurídicas asociadas con la reproducción), por su ejercicio laboral y, por el territorio y las dinámicas asociadas con la criminalidad y la ilegalidad en las que se desenvuelve. Pues cabe mencionar que los territorios del miedo, término acuñado por la antropóloga colombiana Soledad Niño (2000), son espacios marginados de los nodos de desarrollo de las ciudades debido a que son feos, peligrosos y conflictivos. En estos espacios suelen residir y laborar grupos humanos carentes de garantías sociales (habitantes de calle, mujeres, gais y travestis dedicados al ejercicio laboral sexual, vendedores informales, etc.) que, por lo general, practican actividades asociadas con la ilegalidad y la informalidad.

La pregunta que emerge es la siguiente: ¿Qué tanto sabe un habitante de a pie lo que conlleva vivir desde estas opciones? Lo que algunos saben o intuyen sobre esta situación llega a través de los imaginarios.

Desde esa perspectiva, lo que se sabe sobre estas identidades responde a las experiencias directas o indirectas de otras personas, que podrán ser reales o no, y de las impresiones sensibles (visuales, auditivas, olfativas, kinésicas) que reciben de esa porción de ciudad en el diario vivir. En todo caso, unas representaciones (individuales y colectivas) parciales e incompletas con las cuales poder valorar a mi Otro desde lo que sabe, hace y es.

En la Historia de la sexualidad, Michel Foucault (1991) ofrece un panorama muy detallado sobre el modo como la ciencia y la pedagogía abanderaron un discurso de discriminación por los comportamientos sexuales de las identidades periféricas, que se asoció con el pecado, la transgresión jurídica y la enfermedad, justificando así su persecución, encierro o muerte en hospitales psiquiátricos, cárceles y zonas marginales de la ciudad.

De otro lado, la tecnología biomédica contemporánea generó otros registros de saber vinculados con la 'contra-sexualidad', término empleado por Beatriz Preciado (2002). El nacimiento de nuevos cuerpos y nuevos géneros a través de procesos quirúrgicos y cosméticos aseguró la transformación prostética de los cuerpos y alimentó un nuevo temor: sujetos tecnobiológicamente producidos no reproductivos.

Sin entrar en una lectura más profunda, puede deducirse que los imaginarios, la pedagogía y el conocimiento científico trazaron en la marginalidad (del constructo histórico, del saber y del vivir en comunidad) el destino social, cultural y científico de las identidades periféricas.

En el encuentro directo con Leidy, Gia, Valeria, Yuri y Diana, se supo que viven y trabajan en el sector del parque La Libertad hace aproximadamente treinta años, que solo dos de ellas son de procedencia pereirana y que se reconocen como objeto de la marginalidad y discriminación social, cultural y jurídica por su género, por dedicarse a la prostitución y por habitar y laborar en uno de los territorios más miedosos para muchos pereiranos y pereiranas.

Pues lo que más me molesta de las personas es cuando vamos caminando por las calles y nos critican, nos miran, nos huyen. Hay gente que no, pero mucha gente que sí... nos recriminan mucho. [...] Nos tienen como fobia, miedo. Pero mucha gente nos acepta. Hoy en día nos aceptan mucho. Pero en la época mía casi no nos aceptaban. Nos recriminaban mucho. (Leidy, en la crónica audiovisual Días de Afrodita, 2014-2015)

En lo anterior, queda claro que las mujeres transgénero del parque La Libertad no solo son conscientes de la marginalidad en tanto se les identifica como agentes de miedo, sino, sobre todo, que ese miedo emana de la manera particular en que se muestran al mundo.

Lo que se sabía sobre Leidy, Gia, Valeria, Yuri y Diana era prácticamente nada; ese saber estaba arraigado en las representaciones de otras personas, en el efímero contacto visual y perceptual, y por supuesto, en lo que nos ha dicho la ciencia y la religión.

Pero eso de que la gente empiece a hacer una personalidad de uno sin ni siquiera conocerlo, eso es desagradable también. Entonces en este trabajo se nos presentó como esa oportunidad de decirle al mundo iMire! podemos hacer otras cosas, podemos hablar de otras cosas y no solamente de sexo. Porque otra cosa... es que... iay! es que las travestis solamente piensan en sexo. (Gia, en conversatorio sobre género y creación en el Museo de Arte de Pereira, 2015)

El trabajo al que hace referencia Gia es a Vestidos Orales y a su participación como sujeto de saber. Lo que afloró en este proceso fue precisamente el reconocimiento de esa construcción particular del género, a través de la cual las mujeres transgénero son portadoras de experiencia de vida y de un conocimiento que sobrepasa el ejercicio sexual - un ejercicio que además las invalida en otras dimensiones cognitivas, sociales y culturales - que encuentra en la experiencia estético-artística la manera de desmarcarse de esa mirada banal e insultante de la que son objeto.

Queriendo atravesar esa frontera de conocer acerca de mi Otro por imaginario, por pedagogía y por ciencia y no por experiencia vivida, se invitó a estas cinco mujeres a pensar 
conjuntamente en una posibilidad creativa mediante la cual pudieran mostrarle y contarle a la sociedad sus verdades: quiénes son ellas y cómo existen desde esa experiencia identitaria en relación con su contexto.

Después de varios encuentros y conversaciones se coincidió en que el artefacto sensible para reivindicarse públicamente en esa representación identitaria sería el vestido para la Marcha del Orgullo Gay. Acontecimiento artístico que se activaría posteriormente en el Museo de Arte de Pereira.

Reconocerlas como sujetos de conocimiento e invitarlas a producir esa experiencia sensible a través de la cual podrían aparecer como mujeres transgénero fue de lo que se trató Vestidos Orales. En ese sentido, el proceso creativo y la experiencia estética, más que posibilitar una decodificación, tuvo por objeto servir de inductores de un encuentro humano entre ellas, sus verdades y los creadores y creadoras.

Las cinco mujeres transgénero fueron invitadas a la universidad, inicialmente, a los talleres de diseño de vestuario y, posteriormente, al estudio de fotografía. Es importante mencionar que Diana, Valeria, Gia, Yuri y Leidy no habían tenido contacto alguno con la universidad en lo que se refiere a ella como institución de educación superior, pero tampoco como infraestructura arquitectónica, visual y social, es decir, cómo se ve la universidad y cómo se dan las dinámicas de encuentro e intercambio entre las personas que convergen en este entorno. Así que acordar el papel que jugarían en este lugar sería de vital importancia para el proyecto artístico. Como el interés no radicaba en convertirlas en diseñadoras de modas, su participación tomaría forma a través de sus saberes sobre el género y la identidad, a partir de conversaciones con sus diseñadores y diseñadoras.

Acudieron a dos sesiones: la primera, para conversar sobre el vestido soñado. Fue así como surgieron las decisiones estéticas y técnicas sobre los trajes de gala. Diana decidió que quería llevar un traje de gitana; Valeria quería lucir como una garota; Gia soñaba con aparecer como Cleopatra, su personaje preferido del cine; Yuri vislumbraba en la reina Nefertiti la materialización de su vestido; y Leidy quería mostrarse como una dama antigua. En este encuentro se observaron imágenes en internet relativas a estos trajes con el propósito de construir un referente en dibujo y poder decidir - conjuntamente - colores, texturas y materiales para la confección. Luego se procedió a la toma de las medidas y a la elaboración de los moldes. Cada diseñador y diseñadora generó un molde con el cual construyó su proceso de patronaje que consistió en el corte y confección del vestido sobre la base de las plantillas derivadas y las conversaciones sostenidas con Diana, Valeria, Gia, Yuri y Leidy.

Para la segunda sesión, los vestidos ya habían sido elaborados. La presencia de Diana, Valeria, Gia, Yuri y Leidy obedecía a dos intenciones: la primera era para realizar la prueba de vestuario y de styling (peinado y maquillaje), y la segunda, para llevar a cabo la sesión fotográfica con los vestidos puestos.

Pensar, diseñar y producir esos vestidos mediante los cuales se dio sentido a las prácticas, intuiciones y conocimientos de los individuos que participaron de ese acontecimiento artístico llevó a develar unos cuerpos otros, propios, portadores de las inventivas y vitalidades de Diana, Valeria, Gia, Yuri y Leidy. Cuerpos emplazados en otros cuerpos, pues el vestido es en sí mismo otro cuerpo desde el cual se reafirman posturas estéticas, políticas y sociales alrededor del género y la identidad. La existencia de unas poéticas compartidas donde todos y todas fueron creadoras y creadores constituye el principal potencial de la experiencia.

Contrastar en el museo, y en la Marcha, las verdades de ellas y las de los otros generó una multiplicidad de representaciones y juicios (estéticos, simbólicos y políticos) alrededor de esa construcción individual del género. La posibilidad de devenir sensibles (imagen), políticos y sujetos de conocimiento en ese encuentro social llevó a comprender que en el territorio de lo humano somos idénticos.

La combinación de los saberes de las mujeres transgénero y de los creadores y creadoras dio origen a un vestido que les permitió salir del anonimato y aparecer como Leidy, Gia, Valeria, Yuri y Diana. Resulta coherente preguntarse: ¿De qué manera el vestido hace aparecer la identidad? ¿De qué habla el vestido?

\section{Vestidos Orales y las formas de lo sensible: el vestido como la forma del aparecer}

Incorporar el transgenerismo nunca será similar a ser designada por la categoría mujer. La diferencia radica en que el género mujer es una designación, mientras que el transgenerismo es una apropiación, una decisión. Esto es lo que sustenta el valor de nombrar, por eso lo que no se nombra no existe (BUTLER, 2002). Butler explica que, al nacer, lo primero que se nombra es el género: ies una niña! Como el transgenerismo no es una categoría de género que se nombra al nacer, el vestido sirve para expropiar simbólicamente el género mujer y, en consecuencia, su 
nacimiento.

El caso es que cuando una mujer transgénero incorpora el vestido, no expropia el género mujer de forma temporal y simbólica como lo haría la travesti, sino que lo expropia de manera definitiva y política. La mujer transgénero usa el vestido como una manera de reterritorializar, performativa y permanentemente, la categoría mujer, pero además somete su cuerpo a una serie de tratamientos cosméticos y quirúrgicos que le permiten moldear los ideales de la feminidad y en casos más radicales, los del sexo, como en las mujeres transexuales. Por lo tanto, el vestido, más que una forma de hacer aparecer la categoría mujer, es una forma de hacer aparecer la mujer que ha decidido ser, la que ha inventado.

El valor político del vestido en ese aparecer, tanto en el museo como en la Marcha, se sustenta en su capacidad para hablarle a los otros de la deconstrucción de esas investiduras femeninas y masculinas - que dividen a los sujetos y sus cuerpos en dos géneros y en una única forma de erotizar - a través de las cuales nos advierten de un cambio que no es más que la existencia de estos seres y de sus maneras particulares de autoconstruirse, autoconstruir el género, el cuerpo y sus prácticas sexuales. Por esta razón, pero también porque la obra fue concebida a través de la conversación entre ellas, las mujeres transgénero del parque y los creadores y creadoras, se tituló Vestidos Orales.

Lo que interesa reflexionar de esta relación mujer transgénero-vestido-arte es que el vestido como dispositivo relacional de encuentro, interacción y transformación humana permitió que los creadores y creadoras se acercaran a ellas y que ellas se acercaran al mundo. La tarea del arte fue inventar ese dispositivo, crear los medios y modos para elaborarlo y proponer, a través de él, el reconocimiento de estas formas de subjetividad (Imagen 1).

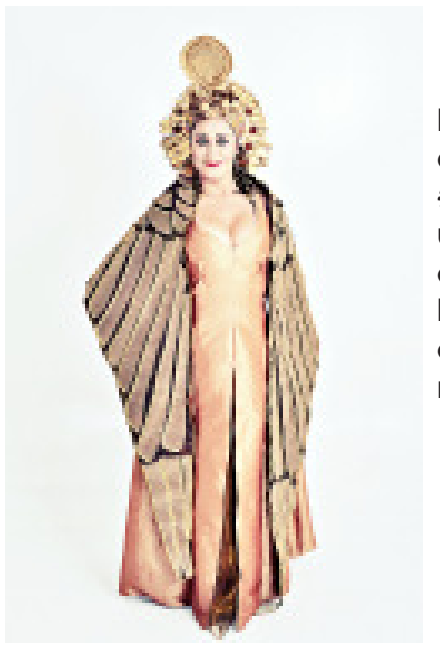

Imagen 1 - Gia posando, durante una sesión fotográfica, con su traje de gala para la Marcha del Orgullo Gay

Fuente: Fotografía tomada por Jessica Quiceno. Diseño de vestuario de Mariana Aristizábal (2014-2015)

\#PraCegoVer Fotografía de una mujer blanca, maquillada, con un adorno dorado sobre la cabeza, usando un vestido recto largo con escote en $\mathrm{V}$, en tonos amarillo ocre, con un recorte delantero hasta el suelo. Sobre el vestido, la mujer lleva una capa marrón clara de tiras verticales. La estética del vestido remite a la representación de la reina egipcia Cleopatra.

Lo sensible no solo habita en el conocimiento y en la percepción. El ser humano también hace experiencia en otros espacios. Uno de ellos es el vestido. Así lo escribe Emanuele Coccia (2011):

El hombre no hace sino adquirir y restituir lo sensible al mundo y no sólo en la estrecha esfera perceptiva. Soñar, dibujar, pero también vestirse, maquillarse o hablar: todas esas actividades [...] son formas de nuestra vida sensible pero que, en cambio, no coinciden con el simple hecho perceptivo". (p. 114)

Esas cosas que no coinciden con el hecho perceptivo coinciden con el hecho creativo, es decir, no basta con adquirir lo sensible, también hay que producirlo (Imagen 2). Solo en esa medida, la multiplicidad y los multiplicadores podrán seguir existiendo como sensibles (imágenes/ vestido) y como formas cognoscibles de lo sensible (arte, diseño, ciencia, tecnología y otros).

Vestirse es incorporarse un sensible, es como ponerse una máscara, pues la máscara es "la paradoja de la medialidad, por la cual nuestro cuerpo es medio, vehículo que nos transforma a nosotros mismos en imagen y nos obliga a apropiarnos de imágenes para dar forma a nuestro cuerpo" (COCCIA, 2011 , p. 126). Pero ¿qué es específicamente lo que expresan el vestido y el acto de vestirse?

La artista española María del Mar Mendoza (2010) provee, a través de su tesis doctoral EI vestido femenino y su identidad: el vestido en el arte de finales del siglo XX y principio del siglo XXI, un dedicado recorrido histórico sobre el vestido en el que señala que:

[...] vestirse no es solo una cuestión de abrigo y adorno, la ropa expresa la singularidad de cada persona, ya sea en su oficio o profesión que desempeña, ya sea indicando los estados de ánimo $o$ el estatus social al que se pertenece o se desea pertenecer. (p. 164) 
Imagen 2 - Diana posando, durante una sesión fotográfica, con su traje de gala para la Marcha del Orgullo Gay

Fuente: Fotografía tomada por Álvaro R. Herrera. Diseño de vestuario de Natalia Grisales (2014-2015)

\#PraCegoVer Fotografía de una mujer blanca, maquillada, llevando un manto largo dorado sobre el pelo negro, aretes negros, collar dorado, un vestido sin tirantes en tonos de rojo y vino, con un adorno de encaje en el escote, cinturón y ruedo dorado. La estética del vestido remite a la representación de una gitana.

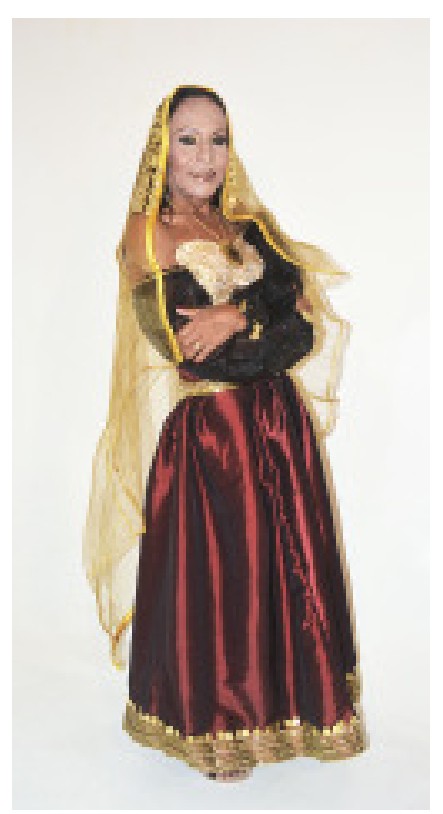

Por su parte, Coccia añade a las cuestiones nombradas por Mendoza que el vestido es el vehículo a través del cual deviene la subjetividad, sus significados y su exteriorización. Ese cuerpo inanimado lleva al mundo una parte de nosotros e incorpora del mundo aquellas cosas que nos hacen sentir reconocidos en esas representaciones que inventamos, apropiamos o aceptamos por designación.

Me gustó, porque... pues es algo que nunca había experimentado y me gustó pues para posar así con este maquillaje y así vestida como estoy, me veo así lo que soy, me veo así lo travesti que soy. El maquillaje está muy bien hecho para una fiesta Gay, está fascinante. (Valeria en entrevista en el video documental Vestidos Orales, 2014-2015)

La potencia del vestido radica, como lo expresan las palabras de Valeria, en su capacidad para llevar al mundo ese sentir subjetivo del género. Ella lo denomina travestismo porque es el nombre que ha conocido para presentarse ante la sociedad. También significa que la vida y la identidad pueden circular en algo diferente al ser humano. Esto es, a través de sus cosas, o sea del vestido. En ese orden de ideas, el vestido es tanto una incorporación performativa de la categoría mujer, como la presentación (política) de la mujer transgénero ante el mundo y ante su propia comunidad (Imagen 3).

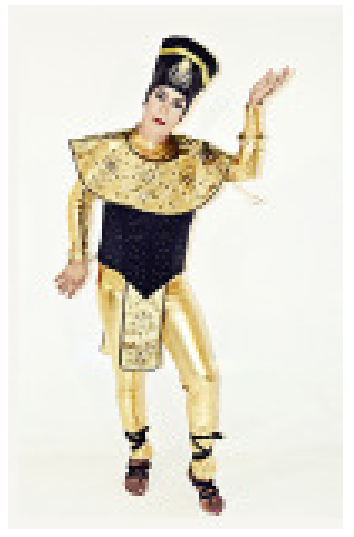

Imagen 3 - Yuri posando, durante una sesión fotográfica, con su traje de gala para la Marcha del Orgullo Gay.

Fuente: Fotografía tomada por Álvaro R. Herrera. Diseño de vestuario de Alejandra Rudas (2014-2015)

\#PraCegoVer Fotografía de una mujer blanca y maquillada, usando un sombrero alto, negro, con adornos dorados, estilo egipcio, blusa negra de mangas doradas y capa dorada con bordes negros, pantalones en tonos dorado, y sandalias de tiritas negras atadas sobre los pantalones. La estética del vestido remite a la representación de la reina egipcia Nefertiti.

El vestido como imagen - entre el mundo y el yo - constituye para Coccia "la fuerza de reconocerse en algo ajeno, que a través del reconocimiento deviene propio" (201 1, p.126). El vestido es, en últimas, para una mujer transgénero, la posibilidad de devenir en el género y en el modo como ha decidido incorporarlo.

Por eso no podían ser los creadores y creadoras (especialistas en diseño de moda y artistas) quienes tomaran las decisiones estéticas y afectivas sobre el vestido. Debían ser ellas - Leidy, Gia, Valeria, Yuri y Diana - quienes indicaran cómo tendrían que ser esos vestidos, cómo querían ser reconocidas y recordadas (Imagen 4). Los creadores y creadoras simplemente jugarían el papel de traductores estéticos y artísticos de esos diálogos y verbalizaciones en códigos de diseño y, a la vez, serían productores y productoras técnicas de los vestidos. 
El vestido, pues, valorado por Butler (2002) como una instancia teatral de la construcción performativa, cumple dos funciones: revelar y rememorar. A pesar de que el vestido fue valorado verbalmente por Leidy, Gia, Valeria, Yuri y Diana como disfraz, su connotación nunca estuvo asociada con encubrimiento.

iEspectacular! El diseño y los colores. El corsé me quedó muy bonito. Me siento muy bien con él. Bueno, para mí es una experiencia que es primera vez en mi vida que yo participo en un disfraz. Yo nunca me había disfrazado. Me han dado una satisfacción, una alegría muy bonita. $Y$ ver el detalle. (Diana en entrevista en el video documental Vestidos Orales, 2014-2015)

Imagen 4 - Leidy posando, durante una sesión fotográfica, con su traje de gala para la Marcha del Orgullo Gay.

Fuente: Fotografía tomada por Jessica Quiceno. Diseño de vestuario de Santiago Cardona (2014-2015)

\#PraCegoVer Fotografía de una mujer blanca, maquillada, lleva puesto un vestido en tonos de vino y rojo oscuro. Es un vestido con escote en $V$ que deja los hombros desnudos y a la vista los tirantes rojos del sostén. La parte superior del vestido, en color vino, termina en $\mathrm{V}$ sobre la falda larga godet. La estética del vestido remite a la representación de una dama antigua.

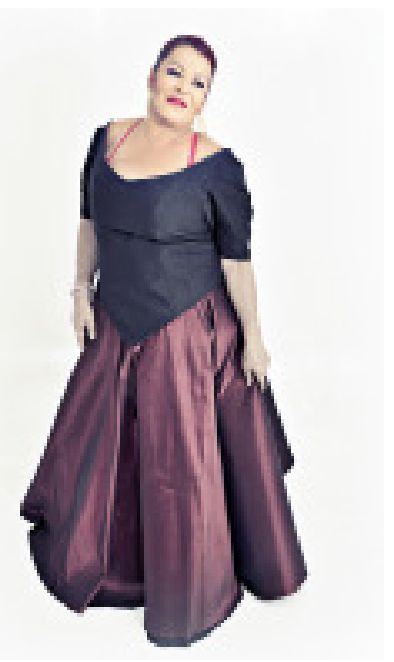

En las palabras de Diana yace algo muy profundo relacionado con el hecho de que el vestido - y correlativamente el disfraz - nos hace a todos y todas. Cuando ella dice que nunca se había disfrazado, cualquiera diría que las mujeres transgénero son gente que vive disfrazada. Habrá que preguntarse ¿qué diferencia hay entonces entre su indumentaria cotidiana y el vestido de gala para la Marcha? ¿Será que es como estar en ropa de trabajo y estar con ropa de domingo? (Imagen 5).

El vestido es un cuerpo, una prótesis, un intermediario entre el mundo y nosotros. Es gracias al vestido que el cuerpo anatómico deviene imagen ante nosotros y ante los demás. Pero también la incorporación del vestido, y de otros sensibles, es lo que nos permite reconocernos como sujetos y como múltiples, y en ese juego de multiplicidad el disfraz es otra forma de aparecer.

Imagen 5 - Valeria posando, durante una sesión fotográfica, con su traje de gala para la Marcha del Orgullo Gay

Fuente: Fotografía tomada por Álvaro R. Herrera. Diseño de vestuario de Camila Castillo (2014-2015)

\#PraCegoVer Fotografía de una mujer blanca maquillada, de pelo marrón lacio largo, lleva puesta una gargantilla dorada, sostenes azules con adorno inferior de tiritas doradas colgantes, minifalda azul con cinturón de tiritas colgantes doradas, manto azul largo trasero, apoyando plumas azules como si fueran alas, y sandalias negras de tiritas, de tacones altos. La estética del vestido remite a la representación de una vedete de carnaval.

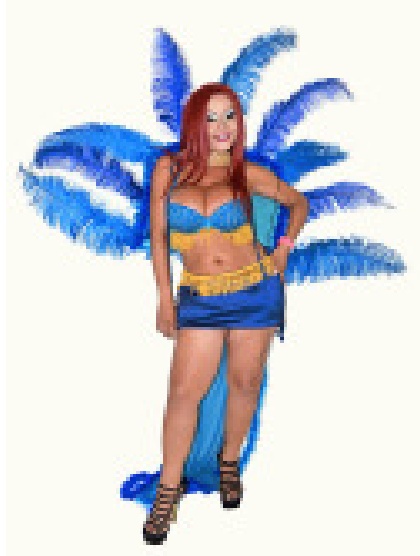

Así que el vestido, o el disfraz, como ellas lo llaman, fue usado para exponer su identidad, para desocultar su verdad. En esa medida, el disfraz en la Marcha debe ser interpretado como una forma de aparecer y de rememorar a Sylvia Rivera. En el libro Malditas. Una estirpe transfeminista, Itziar Ziga (2014) narra la historia de Rivera, considerada la heroína en los disturbios de Stonewall, también activista comprometida con los derechos de la comunidad LGBTI y de las comunidades negras transgénero.

Esa misma puesta en escena durante la Marcha recuerda a todas las identidades queer que lucharon contra las autoridades aquel 28 de junio de 1969 en la revuelta de Stonewall, New York. Revuelta en la que las mujeres transgénero, las travestis, las lesbianas y los gais renunciaron a su disfraz heterosexual. 
La función del vestido es desocultar, exponer, legitimar la identidad. Por eso el vestido es la manera auténtica en que revelan lo que son.

Lucir el vestido significó para estas cinco mujeres transgénero cumplir un sueño: pudieron mostrar su construcción subjetiva como mujeres transgénero y no únicamente como trabajadoras sexuales del parque La Libertad, y simultáneamente, sirvió como mecanismo de inclusión ciudadana, de congregación colectiva y de resistencia, a través del cual fueron visibilizadas como seres con la capacidad para producir opinión, saber:

Me siento muy contenta porque... en una Marcha Gay nunca me había vestido como me voy a vestir hoy, como voy a salir de trincada. Ehhhh... me gusta porque voy a llevar un traje muy muy espectacular, lleno de plumas y de mucho colorido. (Valeria en entrevista en el video documental Vestidos Orales, 2014-2015)

La socióloga argentina Laura Zambrini (2010) indaga sobre las relaciones entre identidades de género y prácticas del vestir y de cómo el vestido ha acompañado la construcción identitaria de los cuerpos. Desde ese plano afirma que las prácticas del vestir, cuyas funciones sociales y simbólicas, basadas en la separación binaria de los géneros (femenino/masculino) desde la época de la modernidad, han estado en permanente tensión y negociación respecto de aquellas identidades que divergen del modelo heteronormativo:

[...] clasificar implica, por un lado, jerarquizar y por otro, naturalizar como legítimas ciertas identidades (incluyendo cuerpos, formas de vestir y actuar) en detrimento de otras que son desplazadas a las zonas de la alteridad. Al normalizar una identidad se le brinda a la misma los atributos positivos que la ubican en el lugar de la "normalidad", y la establece como punto de referencia central para ubicar otras posiciones de sujeto. (ZAMBRINI, 2010, p. 145)

Entonces, cuando el vestido femenino aparece incorporado por un cuerpo masculino, como es el caso de Leidy, Gia, Valeria, Yuri y Diana, los patrones hegemónicos de la identidad son subvertidos. Como dispositivo estético y político el vestido refuerza la oposición de las identidades transgénero a ese ordenamiento jerárquico y binario del género, y se implanta en la sociedad más que como un objeto que remite al ámbito de la feminidad o al fenómeno de la moda, como un dispositivo que crea nuevos cuerpos.

En La profundidad de la apariencia. Contribuciones a una teoría del diseño de vestuario la diseñadora Claudia Fernández (2015) plantea que la imagen que el ser humano crea de sí mismo es la imagen de su cuerpo. En ese sentido, la función del vestido es servir de interface entre la imagen mental y el cuerpo:

[...] el cuerpo actúa como imagen del ser humano, es su manera de aparecer y de materializarse, pero a su vez, esta imagen de ser se ha construido a partir de otras imágenes que lo preceden y sobre las cuales no tiene dominio, pues sus significados y formas de representación lo han dado otros". (FERNÁNDEZ, 2015, p. 88)

Si trasladamos esta reflexión a los vestidos de Vestidos Orales, se pueden deducir dos funciones: visibilizaron esa 'verdad interna' sobre la identidad transgénero y sirvieron de conductores de la experiencia corporal (física y cultural) de estas identidades. Eso significa que el compromiso antropológico y estético del vestido fue hacer aparecer nuevas y múltiples configuraciones de la subjetividad. En otras palabras, nuevos cuerpos.

En suma, el proceso creativo dio acceso a varios contornos de saber: el saber del arte, del diseño y del género. Pero también hizo posible el diálogo con la estructura académica y hegemónica del conocimiento. Cabría decirse que se le apostó a la elaboración de un conocimiento plural, colectivo y situado que encontró en el cuerpo, en la imaginación y en la subjetividad otros valores constitutivos del saber. Esto significó valorar el conocimiento y la mirada del Otro porque el Otro construye una de las dimensiones que conforman la topografía subjetiva. En ese sentido, el conocimiento es una elaboración colectiva de sujetos (mujeres transgénero, creadores y creadoras) que fueron capaces de unirse, de ver, pensar y decidir uno junto al otro, sin pretender ser el otro.

\section{Conclusiones}

Marian CAO (2011) nos recuerda que la historia del arte no ha sido generosa con las mujeres. Desde la Antigüedad, pasando por la Edad Media y hasta el Renacimiento, fueron los hombres los que ostentaron el título de genio creador. La asociación de la mujer con la dimensión emocional, el deseo sexual y la vida privada sirvió para justificar su incapacidad como creadora.

Con estos valores, el patriarcado ha obstaculizado la visibilización de la mujer como sujeto político y de saber. Al no permitir que se represente como sujeto, le niega la oportunidad de expresar su individualidad y, por consiguiente, su diferencia. Ser designada como el Otro no entreteje una relación de igualdad con el hombre. Es su otro, no su par. 
De tal manera que producir nuevas imágenes (de mujeres), rediseñar rutas conceptuales para tratarlas y darles peso epistémico se convirtió en una obligación para las mujeres en la contemporaneidad.

Hoy, cuando los límites del sistema binario (sexo/género) y los valores antes circunscritos a la hegemonía heteropatriarcal han sido subvertidos por las mujeres, las matrices culturales, sociales y estéticas que la sujetaron comienzan a revertir en nuevas prácticas de subjetividad. Y en el campo del arte, esas prácticas de subjetividad, en tanto prácticas de conocimiento, encontraron el modo de aparecer y ser reconocidas.

La contribución del arte ha sido producir nuevos correlatos (simbólicos, éticos, estéticos y políticos) a través de los cuales se han hecho visibles y sensibles los cuerpos y sexualidades excluidas por el sistema de normalización dominante. Como explica Nelly Richard (1996), las prácticas artísticas han producido nuevos reajustes estéticos que revalorizan la experiencia con el objeto de "privilegiar - a favor de las mujeres - lo vivido" (RICHARD, 1996, p.735).

Hablar de experiencia es apelar a una idea de conocimiento situado, localizable en los sujetos y en sus cuerpos (heterogéneos, diversos, marcados por los conflictos, por las determinaciones sexuales) que encuentra en las formas de la negación, la marginalidad y la opresión otras maneras de producir saber y subjetividad:

la "experiencia" sería la base material-corporal que sustenta un conocimiento vivenciado desde la naturaleza (cuerpo) o desde la biografía (vida): un conocimiento no mediatizado por la ideología de la razón, un conocimiento in-mediato. (RICHARD, 1996, p. 735)

La masculinidad, también la feminidad, así como las prácticas de deseo, hallaron norte en otras identidades. Darles imagen a esas identidades y nombrarlas desde el discurso de la estética y el arte también fue el propósito de Vestidos Orales. La creación y lo sensible como espacios mediales para hacer cognoscibles esas construcciones de género y para incorporar nuevas representaciones de la subjetividad, produjo una transformación mutua, emocional, estética y cognitiva, a través de la cual se hizo patente que tanto las mujeres transgénero como los creadores y las creadoras tenemos cosas en común que discutir, inventar y resignificar.

Encontrar en el arte y la estética el recurso para hacer actuar esas identidades y esas representaciones individuales y colectivas supuso valorar los criterios estéticos y cognitivos de ambas partes. Las mujeres transgénero hicieron visible ese saber subjetivo sobre la construcción del género y, los creadores y las creadoras hicieron visible su saber subjetivo y colectivo de las imágenes. El género como autorrepresentación y como co-representación permitió generar la combinación de las sinergias cognitivas y estéticas desde las dos perspectivas.

Por eso la importancia de este encuentro radicó en la capacidad de los sujetos para producir nuevas organizaciones del saber que, basadas en la cooperación y la diferencia, permitieron vivir en situaciones de permanente reinvención sin dislocar la posibilidad de transitar y reterritorializar el saber y la subjetividad.

\section{Referencias}

ASPRILLA, Ligia. "Los productos de la creación-investigación: la producción de conocimientos desde el arte". In: ASAMBLEA GENERAL DE LAASOCIACIÓN COLOMBIANA DE FACULTADES Y PROGRAMAS DE ARTES- ACOFARTES, Cali, Instituto Departamental de Bellas Artes. Cali: Instituto Departamental de Bellas Artes, 2013. p. 1-65.

BORGDORFF, Henk. El debate sobre la investigación en las artes. Amsterdam, 2006. Disponible en http://www.konst.gu.se/digitalAssets/1322/1322698_el-debate-sobre-la-investigaci-n-en-lasartes.doc. Acceso el 26/09/2018.

BUTLER, Judith. Cuerpos que importan. Sobre los límites materiales y discursivo del "sexo". Buenos Aires: Paidós, 2002.

BUTLER, Judith. El género en disputa. El feminismo y la subversión de la identidad. Barcelona: Paidós, 2007.

CAO, Marian. Mulier me fecit. Hacia un análisis feminista de arte y su educación. Madrid: Horas y Horas, 2011.

COLCIENCIAS. Modelo de medición de grupos de investigación, desarrollo tecnológico o innovación y de reconocimiento de investigadores del sistema nacional de ciencia, tecnología e innovación. Bogotá, 2015. Disponible en http://www.colciencias.gov.co/sites/default/files/upload/ noticias/mediciondegrupos-actene2015.pdf. Acceso el 26/09/2018.

DE LAURETIS, Teresa. "La tecnología del género". In: DE LAURETIS, Teresa. Technologies of Gender: essays on theory, film and fiction. London: Macmillan Press, 1989, p. 1-30. Disponible en http:// 
blogs.fad.unam.mx/asignatura/adriana_raggi/wp-content/uploads/2013/12/teconologias-delgenero-teresa-de-lauretis.pdf. Acceso el 30/09/2018.

FERNÁNDEZ, Claudia. La profundidad de la apariencia. Contribuciones a una teoría del diseño de vestuario. Medellín: Universidad Pontificia Bolivariana, 2015.

FOUCAULT, Michel. Historia de la sexualidad I. La voluntad de saber. Madrid: Siglo veintiuno editores, 1991.

HARDING, Sandra. Ciencia y feminismo. Madrid: Ediciones Morata, 1996.

HERNÁNDEZ, Fernando. "La investigación basada en las artes. Propuestas para repensar la investigación en la educación”. Revista Educatio Siglo XXI, Murcia, n. 26 p. 85-118, dic., 2008.

MAFFÍA, Diana. "Epistemología feminista: La subversión semiótica de las mujeres en la ciencia". Revista venezolana de estudios de la mujer. Caracas, v. 12, n. 28, p. 63-97, ene/jun., 2007.

MARTíNEZ, Luis Adolfo. "Planeación del desarrollo y violación a los derechos humanos: Risaralda y la 'reinvención del territorio'”. Revista Universitas Humanística, Bogotá, n. 73, p. 107-144, ene/jun., 2012.

MENDOZA, María del Mar. El vestido femenino y su identidad: el vestido en el arte de finales del siglo XX y principio del siglo XXI. 2010. Tesis (Doctorado en Bellas Artes, Departamento de Dibujo) Facultad de Bellas Artes de la Universidad Complutense de Madrid, Madrid, España.

NELSON, Robin. Practice as research in the arts. Principles, protocols, pedagogies, resitances. Nueva York: Palgrave Macmillan, 2013.

NEWBURY, Darren. "Research training in the creative arts and design". In: BIGGS, Michael; KARLSSON, Henrik (Eds). The routledge companion to research in the arts. Nueva York: Routledge, 2012. p. 368387.

NIÑO, Soledad. "Territorios del miedo en Santafé de Bogotá (Colombia)". Investigación \& Desarrollo, Bogotá, v. 8, n. 2, p. 170-179, abr., 2000.

RICHARD, Nelly. "Feminismo, experiencia y representación”. Revista lberoamericana, Pittsburgh, n. 176-177, p. 733-744, jul/dic., 1996.

SILVA, Sandra. "La investigación-creación en el contexto de la formación doctoral en diseño y creación en Colombia". Revista de investigación, desarrollo e innovación, Duitama, v. 7, n. 1, p. 4961, jul/dic., 2016. DOI: 10.19053/20278306.v7.n1.2016.5601

SILVA, Sandra. Vestidos Orales. Video. Pereira, 2014-2015. Disponible en https://www.youtube.com/ watch?v=10bYEwrkjh8\&t=3s. Acceso el 28/09/2018.

SILVA, Sandra. Conversatorio sobre género y creación. Video. Pereira, 2015. Disponible en https:// www. youtube.com/watch?v=Z4abtjUWHig. Acceso el 28/09/2018.

SULLIVAN, Graeme. Art practice as research. Inquiry in the visual art. Pennsylvania: Sage Publications, 2005.

ZAMBRINI, Laura. "Modos de vestir e identidades de género: reflexiones sobre las marcas culturales en el cuerpo". Nomadías, Santiago de Chile, n. 11, p. 130-149, jun., 2010. DOI: 0.5354/07190905.2010 .15158

ZIGA, Itziar. Malditas. Una estirpe transfeminista. Tafalla: Txalaparta, 2014.

Sandra Johana Silva-Cañaveral (silviaart@hotmail.com) actualmente es profesora de planta del Departamento Artes Visuales y Estética de la Universidad del Valle, Cali. Graduada como Licenciada en Artes Visuales de la Universidad Tecnológica de Pereira, con una especialidad en Artes Mediales en el Programa Online de la Universidad de Caldas de Colombia en convenio con la Universidad Nacional de Córdoba, Argentina y la Universidad de Chile, y Doctora en Diseño y Creación de la Universidad de Caldas. 


\section{COMO CITAR ESTE ARTÍCULO DE ACUERDO CON LAS NORMAS DE LA REVISTA}

SILVA-CAÑAVERAL, Sandra Johana. "La práctica artística como lugar de visibilización de las mujeres transgénero de Pereira (Colombia)". Revista Estudos Feministas, Florianópolis, v. 27, n. 3, e57219, 2019.

\section{CONTRIBUCIÓN DE AUTORÍA}

No se aplica.

\section{FINANCIACIÓN:}

Este artículo deriva de la investigación doctoral titulada: "Vestidos Orales y la visibilización de las identidades transgénero en el arte. Una reflexión en torno a la relación entre creación e investigación" financiada por la Convocatoria № 568 Doctorado Nacional de Colciencias, Departamento Administrativo de Ciencia, Tecnología e Innovación de Colombia.

\section{CONSENTIMENTO DE USO DE IMAGEM}

No se aplica

APROVAÇÃO DE COMITÊ DE ÉTICA EM PESQUISA

No se aplica

\section{CONFLITO DE INTERESSES}

No se aplica

\section{LICENÇA DE USO}

Este artigo está licenciado sob a Licença Creative Commons CC-BY Internacional. Com essa licença você pode compartilhar, adaptar, criar para qualquer fim, desde que atribua a autoria da obra.

\section{HISTÓRICO}

Recebido em 23/05/2018

Reapresentado em 06/10/2018

Aprovado em 18/10/2018

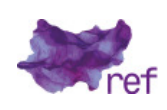

